\title{
Influence of Vetiver Root System on Mechanical Performance of Expansive Soil: Experimental Studies
}

\author{
Guiyao Wang, ${ }^{1}$ Yonggang Huang $\mathbb{D}^{1}{ }^{1}$ Runfa Li, ${ }^{1,2}$ Jingmei Chang, ${ }^{1,3}$ and Jinliang Fu ${ }^{1,4}$ \\ ${ }^{1}$ School of Civil Engineering, Changsha University of Science and Technology, Changsha 410114, China \\ ${ }^{2}$ China Railway Siyuan Engineering Group Co., Ltd., Wuhan 430063, China \\ ${ }^{3}$ CCCC First Highway Fifth Engineering Co., Ltd., Langfang 065201, China \\ ${ }^{4}$ China CEC Engineering Corporation, 410114 Changsha, China \\ Correspondence should be addressed to Yonggang Huang; huangyounger@163.com
}

Received 6 December 2019; Revised 4 July 2020; Accepted 18 July 2020; Published 6 August 2020

Academic Editor: Fan Gu

Copyright ( 2020 Guiyao Wang et al. This is an open access article distributed under the Creative Commons Attribution License, which permits unrestricted use, distribution, and reproduction in any medium, provided the original work is properly cited.

\begin{abstract}
In order to study the influence of the vetiver root system on the swelling characteristics and crack resistance of expansive soil, vetiver grass root growth and its vertical distribution were investigated by the cultivation test and observation. The expansion rate experiment without load and expansive force tests was conducted on planted grass root soil samples, and the effect of the root content on the expansion rate and force of soil mass was analyzed. Finally, the effects of different vetiver contents on the crack resistance of expansive soil were studied by soil cracking experiments in an outdoor natural environment. The results showed that on account of the reinforcement effect of crisscrossing and winding grassroots, the expansion rate and expansive force can be reduced by the grass roots, and the grass roots can significantly increase the anticracking properties of the root-soil composites. From the surface down, the inhibition effect of the vetiver root on the expansive soil appeared from low to high and then decreased; the effect was optimal in the layer of $10 \sim 15 \mathrm{~cm}$. Compared with the pure expansive soil, the swelling force of the cultivated root expansive soil growing for $180 \mathrm{~d}$ decreased by more than $80 \%$, and the unloaded expansive soil reduced by more than $70 \%$. Compared with pure expansive soil, the swelling force and the unloaded expansion rate of cultivated root expansive soil growing for $90 \mathrm{~d}$ decreased by more than $50 \%$.
\end{abstract}

\section{Introduction}

Expansive soil is multifractured, also called as "cracked soil," and cracks have a significant impact on strength index and slope instability [1]. Therefore, the instability mechanism and treatment aspects of expansive soil slopes have been widely studied [2-6]. The existing protection methods are roughly divided into two categories [7]: limiting crack development and not limiting crack development. Not limiting crack methods were directly applied to deal with expansive soils, such as the retaining structure method, slope protection method, geotechnical bag method, and physical improvement method. The main methods for restrictive crack development include the geomembrane method, algorithm change, and chemical improvement method and achieve targeted protection from the perspective of water and particles.
In recent years, more and more scholars paid more attention to the ecological slope protection, and the impact of vegetation on soil cracking has appeared. For example, Li et al. [8] found that short-term rainfall and evaporation process have little effect on the water holding capacity of expansive soil under the vegetation cover. Xie et al. [9] found that erosion occurs on the slope surface, which can be prevented by vegetation due to the interception effect. Larger leaf area and greater root depth can reduce the water content in the soil, contributing to the increase in shear strength. Thereby, vegetation on expansive soil slopes is normally suggested [10-14]. The change in water content is the main reason for the fracture of expansive soil [1]. In addition, their findings indicate that vegetation evaporation could slow down the cracking process of the expansive soil. The distribution of roots in soil is a more complicated problem. 
Some scholars have studied the mechanical effects of roots on composite soils and found that the existence of roots could enhance the strength of composites [15-20]. On this basis, Wang et al. [21] show that rice straw can slow the cracking of reinforced soil and declared that the best rate of rice straw is $0.3 \%$. Li [22] believed that plant roots agglomerate soil particles and limit soil cracking. Zhang et al. [23] studied the dry shrinkage of the farmland soil and found that when the root content was larger, the fracture area density was smaller and the fracture length density was larger. Zhou et al. [24] analyzed the strengthening mechanism of the plant root system from the perspective of composite materials and believed that the root fiber played an anticrack strengthening role in the composite materials of root and soil. These results indicate that the reinforced action of rice straw, roots, etc., can improve the structure of the soil and restrict the cracking of the soil.

Because vetiver has a strong vitality and a developed root system, it is commonly used to deal with the slope stability problem [25]. However, little literature has paid attention to its reinforced function. Guo et al. [26] and Bao et al. [27] have discussed the characteristics of vetiver and black locust plants and the technical methods of planting and compared the effects of other methods to control slope collapse and its social and economic benefits and feasibility. The results showed that planting vetiver and hedgehog plants could enhance the slope stability and prevent landslides. Zhou et al. [28] carried out a confined expansion test and a direct shear test on expansive soils with different initial water contents, and the results have shown that the vetiver root system could reduce the expansive force and increase the shear strength. But, the experimental soil sample was a remodeled root-soil complex without considering the effect of actual planting roots on expansive soil.

In summary, most literature studies mainly focus on the general soil quality, and there are few studies which paid attention to the expansion and cracking and shrinkage deformation of expansive soil. Although the use of vetiver and other ecological protection methods to treat expansive soil slope disease has been used more and more, the design and construction are mostly based on the experience of engineers, and there is no theoretical support. Therefore, the research on the influence of the vetiver root system on the swelling characteristics and crack resistance of expansive soil has an important theoretical significance and engineering application value to inhibit the expansion mechanism of expansive soil and dry shrinkage cracking.

\section{Experimental Setup}

2.1. Test Soil. The soil samples were taken from Changsha Shuxiang Road, Hunan, China. They were passed through a $2 \mathrm{~mm}$ sieve. According to the SL237-1999 Geotechnical Test Procedure, the free expansion ratio, maximum dry density, liquid limit water content, plastic limit water content, and the optimum moisture content were determined. The test results are shown in Table 1. According to the JTJ031-95 "Classification of Highway Subgrade Design Code" (China), the soil was classified as weak expansive soil.

\subsection{Experimental Design}

2.2.1. Vetiver Root System. In order to realistically simulate the actual planting environment, three compaction degrees of $95 \%, 92 \%$, and $90 \%$, respectively, were chosen. A height of $5 \mathrm{~cm}$ was for 1 layer to control compaction degrees. The planted soil was divided into three layers and compacted in a compaction mold with an inner diameter of $19.8 \mathrm{~cm}$. After compaction, the compactness of soil from the bottom to top of the mold was 95\%, 92\%, and 90\%, respectively. Taking $95 \%$ compaction as an example, the soil layer height is $5 \mathrm{~cm}$ and the water content is $20.5 \%$. Firstly, the required soil quality was calculated, and then the soil was added to compaction molds with a height of $5 \mathrm{~cm}$ twice. The rest of the different compaction soil layers are made with reference to this. According to this method, a $15 \mathrm{~cm}$ soil column is obtained. Considering that the expansive force is positively correlated with the compactness and the root coefficient decreases with the increase in the buried depth, it is considered that the soil layer with large compaction is close to the surface. When the $15 \mathrm{~cm}$ high soil column is taken out from the mold, with the $95 \%$ compaction soil layer on the top and the $90 \%$ compaction soil layer under the bottom, it is poured into the PVC pipe and then shaved on the upper surface. According to the same upper and lower order, a soil column is placed in the PVC pipe together with the soil column in the pipe spliced into compacted soil with a height of $30 \mathrm{~cm}$ (Figure 1), so that the soil layer with high compaction is close to the ground.

In order to keep the vetiver grass alive, a $10 \mathrm{~cm}$ height of loose planting soil was added to the surface of the compacted soil, and the planting soil was removed while sampling to retain only the compacted soil. Six seedlings were planted per PVC pipe. As the vetiver roots developed into the compacted soil to form a root-soil complex, 24 sets of samples were prepared according to this method (Figure 2).

\subsubsection{Experimental Procedure of Expansive Force for Planted} Soil. After 90 days and 180 days, the root-soil complex in the cultivation tube was taken out. The upper stem and leaf parts were cut off and the planting layer was removed. The soil cake was cut into 6 layers, and the height of the layer was $5 \mathrm{~cm}$. To determine the sampling position of the ring knife, the distribution position of the root system in the cross section was observed. The ring cutter has a diameter of $61.8 \mathrm{~mm}$ and a height of $20 \mathrm{~mm}$.

According to the Trade Standard of P. R. China (SL237-025 1999), the no-load expansion rate test was carried out. As shown in Figure 3, the instrument was calibrated before testing. Unlike the no-load expansion rate test, the expansive force test replaces the hanging plate with a sand-filled bucket and replaces the weight with iron sand according to the Trade Standard of P. R. China (SL237-027 1999). The expansive force was measured by the equilibrium press method, and it was calculated by weighing the sand with an electronic balance with an accuracy of $0.1 \mathrm{~g}$. 
TABLE 1: Basic parameters of the test soil.

\begin{tabular}{|c|c|c|c|c|c|c|}
\hline Index & $\begin{array}{c}\text { Optimum water content } \\
(\%)\end{array}$ & $\begin{array}{l}\text { Maximum dry density } \\
\left(\mathrm{g} \cdot \mathrm{cm}^{-3}\right)\end{array}$ & $\begin{array}{c}\text { Free swelling ratio } \\
(\%)\end{array}$ & $\begin{array}{c}\text { Plastic limit } \\
(\%)\end{array}$ & $\begin{array}{l}\text { Liquid limit } \\
(\%)\end{array}$ & $\begin{array}{l}\text { Plastic } \\
\text { index }\end{array}$ \\
\hline Value & 20.5 & 1.56 & 50 & 23.9 & 53.5 & 29.6 \\
\hline
\end{tabular}

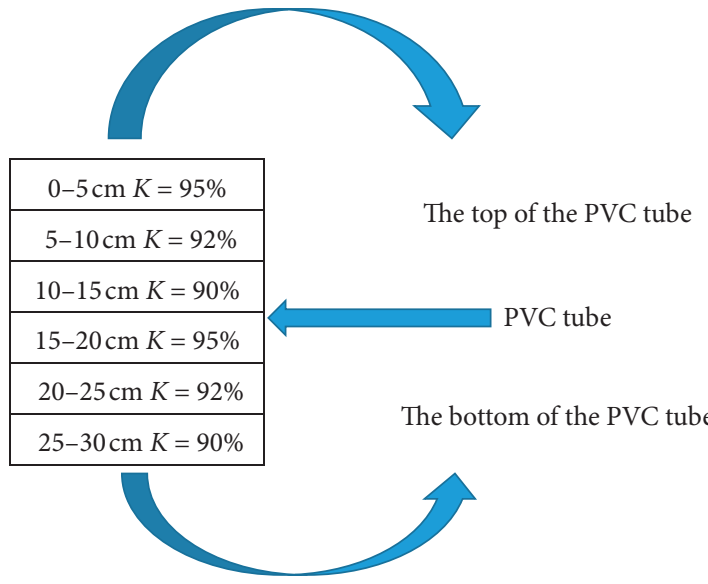

FIGURE 1: Compaction diagram.

For the statistical of the root content, the samples were collected after the end of the test. Then, samples were soaked in clean water for $2 \sim 3 \mathrm{~h}$. After the soil was completely disintegrated, the solution was passed through the $0.25 \mathrm{~mm}$ sieve. Then, the roots of the filter surface were rinsed with water to obtain the grass roots. The root content was weighed and calculated according to the following formula:

$$
\delta=\frac{m}{v}
$$

where $\delta$ is the root content, $m$ is the mass of the root, and $v$ is the volume of the soil.

2.2.3. Experimental Procedure of Dry Shrinkage Cracking for Grafted Soil. The influence of different root contents on the cracking characteristics of expansive soil was studied by laboratory simulation experiments.

The soil samples were divided into 5 parts with a mass of $4.5 \mathrm{~kg}$ each. Four parts of the soil samples were added with 4 parts of the root system, which were $39,78,117$, and 156, respectively, and then fully mixed. The root system with a length of $50 \mathrm{~mm}$ and a diameter of $1 \mathrm{~mm}$ was added. Five soil samples were packed into the container with a size of $300 \mathrm{~mm} \times 200 \mathrm{~mm} \times 100 \mathrm{~mm}$, respectively. The sample height was $5 \mathrm{~cm}$ and was saturated.

The containers were placed outside for illumination. The samples were observed three times a day, which were at 6 am, 12 noon, and $6 \mathrm{pm}$. When cracks appeared, the frequency of observation was increased. The parameters were tested including cracking time, crack width (Figure 4), and temperature. When the crack width is greater than $10 \mathrm{~mm}$ and there is no change for 6 hours, the observation is stopped.

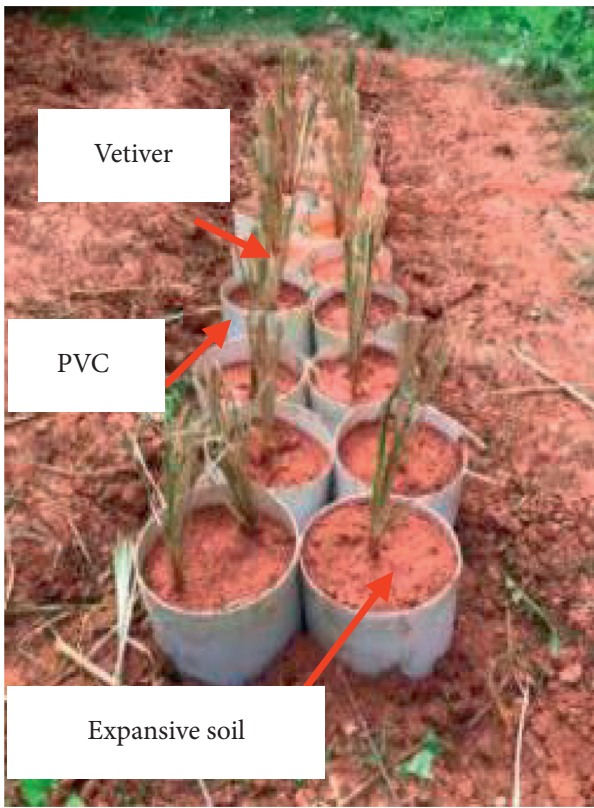

Figure 2: Vetiver cultivation.

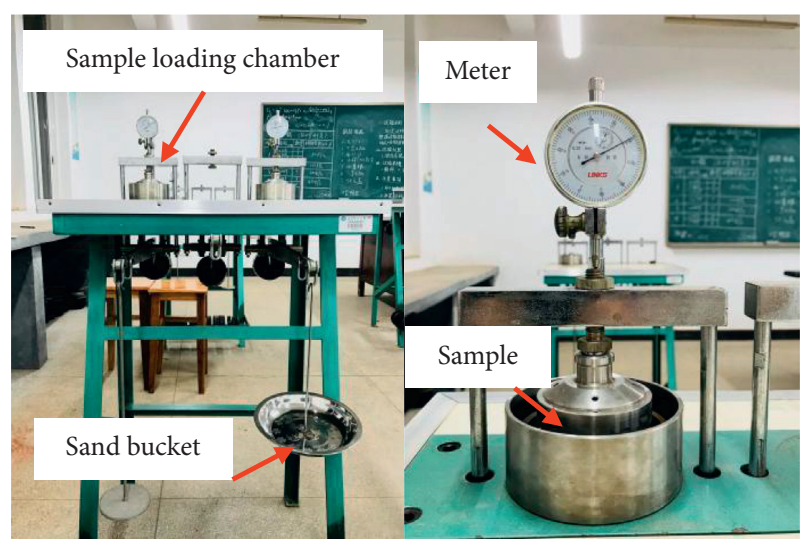

Figure 3: Consolidometer and sample loading chamber.

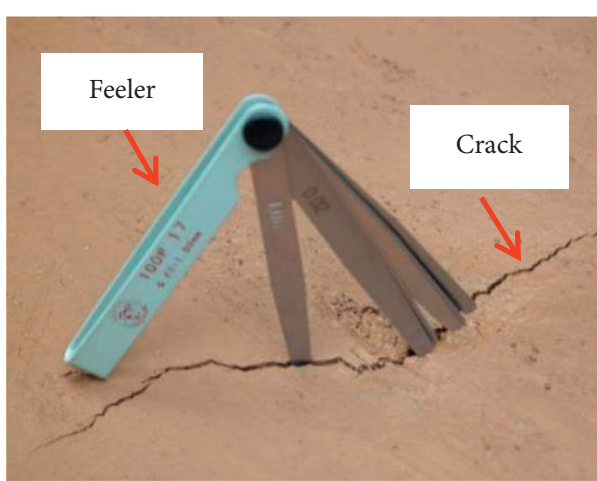

FIGURE 4: Measuring the crack width. 


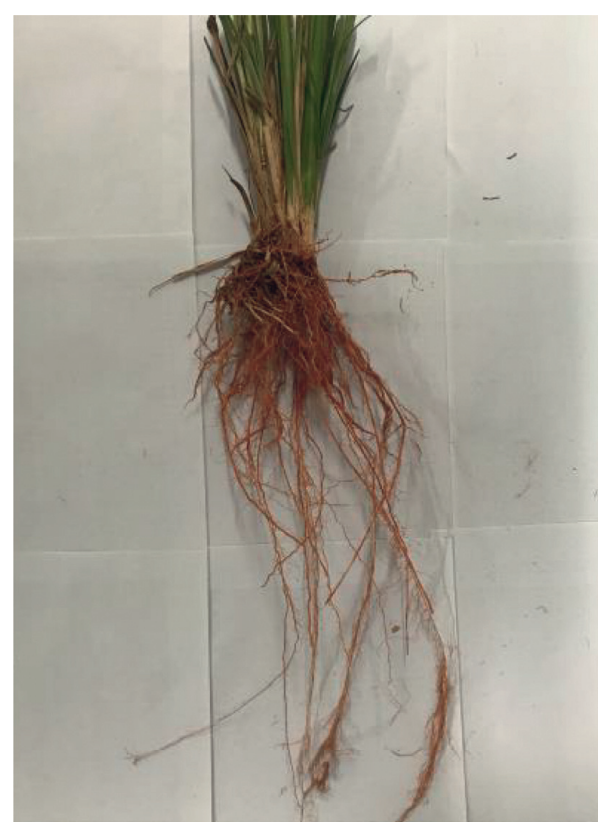

(a)

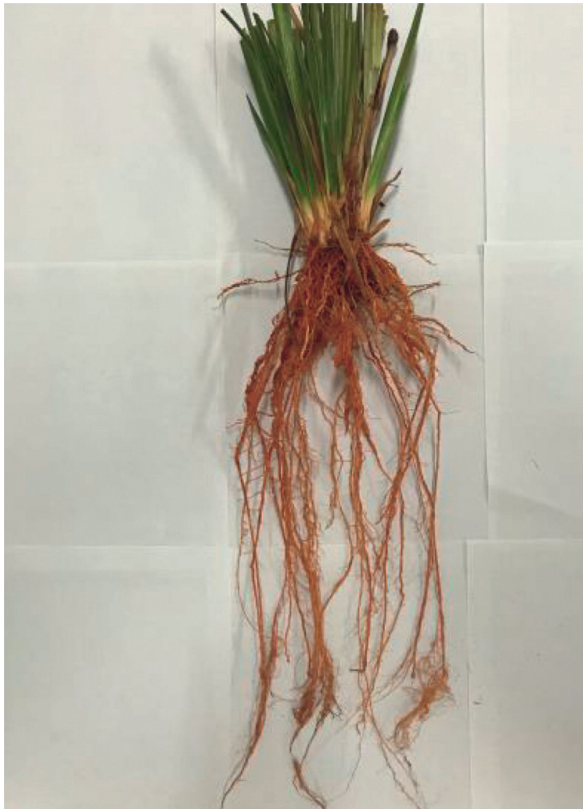

(b)

Figure 5: Root distribution: (a) 90 d; (b) $180 \mathrm{~d}$.

\section{Results and Discussion}

3.1. Root Appearance and Growth Distribution. After 90 days and 180 days, the distribution of vetiver growth is shown in Figure 5. The root diameter of $90 \mathrm{~d}$ vetiver in the range of $0 \sim 20 \mathrm{~cm}$ is mostly more than $1 \mathrm{~mm}$, and the root diameter is less than $1 \mathrm{~mm}$ in the depth range of $20 \sim 30 \mathrm{~cm}$. At the same depth, in the situation of $180 \mathrm{~d}$, the root of vetiver is thicker and denser than that of $90 \mathrm{~d}$. Figure 6 shows that with the increase in the depth of the soil layer, the amount of root coefficient decreases.

\subsection{The Influence of Root System on the Expansion Rate of} Planted Root-Soil Complex. Figure 7 shows the variations of the no-load expansion rate with time. The development of expansive force can be divided into three stages: water absorption expansion, accelerated expansion, and slow expansion. The root accelerates the expansion potential of the expansive soil during the water-swelling stage. When the expansion potential is released to a certain extent, the root system has an inhibitory effect on the expansion potential.

Figure 7 shows that the no-load expansion ratio of the $180 \mathrm{~d}$ root-soil composite is less than that of $90 \mathrm{~d}$ in the same depth range, and the no-load expansion ratio of the $90 \mathrm{~d}$ and $180 \mathrm{~d}$ root-soil composites is smaller than that of the pure soil, indicating that the root system can suppress the expansion ratio. In addition, with the increase in the root content, the ability to inhibit the expansion rate is also improved.

In the situation of $180 \mathrm{~d}$, the no-load expansion rate of root-soil was determined for the depth range of $0-30 \mathrm{~cm}$ with $5 \mathrm{~cm}$ intervals, compared with that of pure soil, and the maximum no-load expansion rate reduction for soot

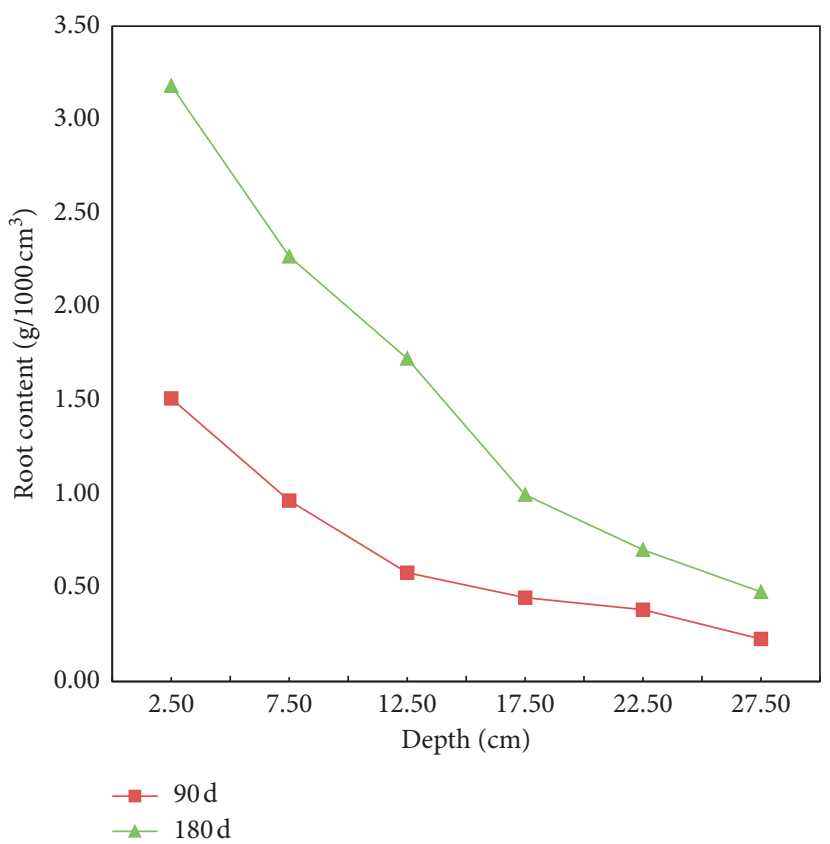

FIGURE 6: Root rate change trend with depth.

soil was $40.9 \%, 60.6 \%, 70.9 \%, 50.8 \%, 42.7 \%$, and $44.5 \%$, respectively. Meanwhile, in the situation of $90 \mathrm{~d}$, the maximum no-load expansion rate reduction for soot soil was $59.1 \%, 37 \%, 56.4 \%, 29.3 \%, 27.4 \%$, and $20.9 \%$, respectively.

From the surface of the soil to the bottom, the influence of the inhibition ability of the root system on the expansive soil increased and then decreased, and the best areas of inhibition ability occurred in the height of $10 \sim 15 \mathrm{~cm}$. 


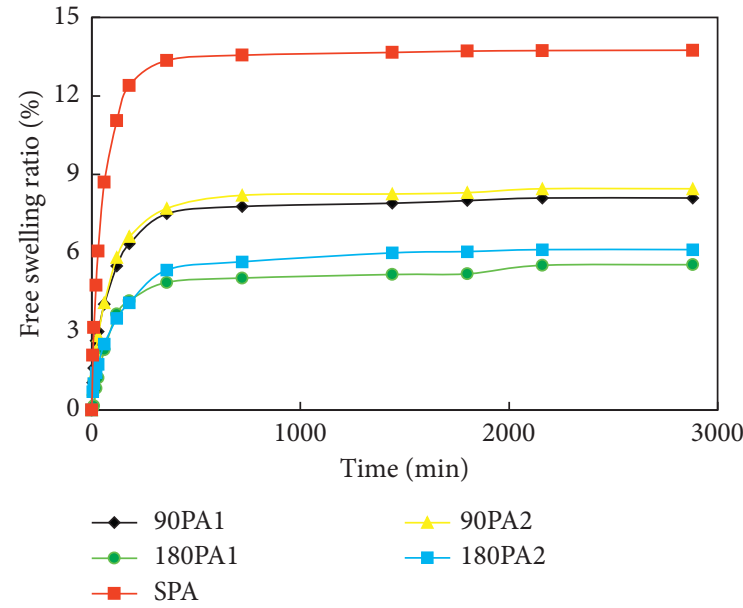

(a)

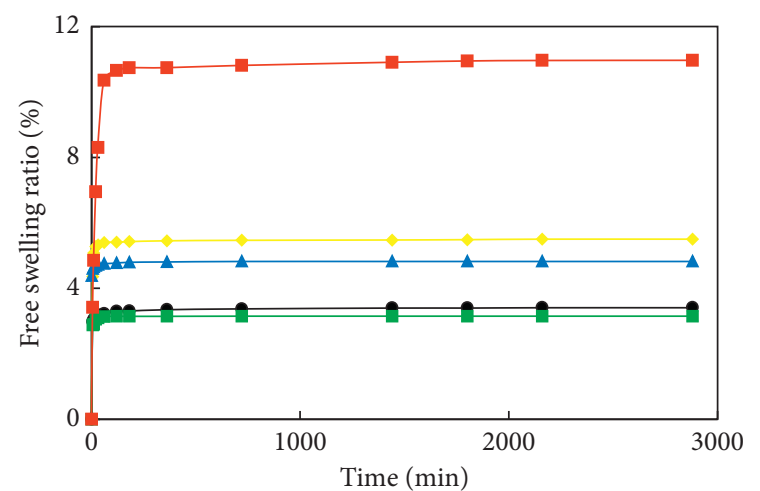

$-90 \mathrm{PC} 1$

$\rightarrow 180 \mathrm{PC} 1$

$\rightarrow \mathrm{SPC}$

$\triangle$ 90PC2

$-180 \mathrm{PC} 2$

(c)

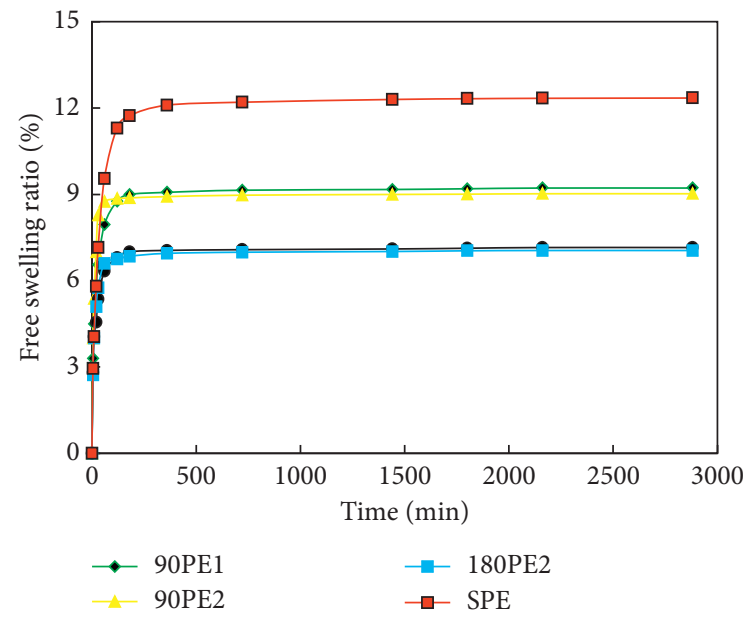

(e)

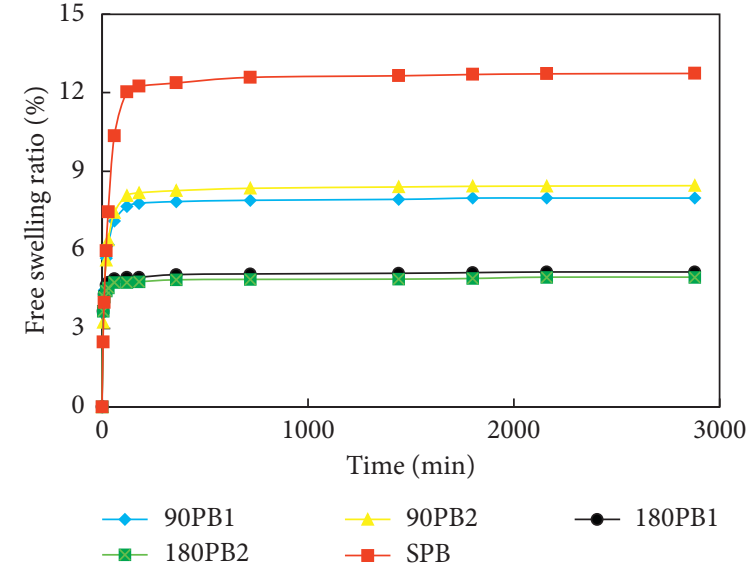

(b)

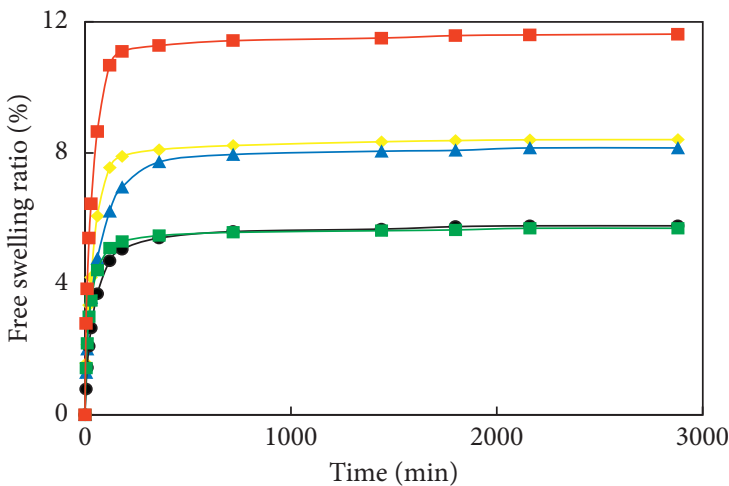

$\longrightarrow$ 90PD1 $\rightarrow$ 90PD2

$\rightarrow$ 180PD1

$\rightarrow-180 \mathrm{PD} 2$

- SPD

(d)

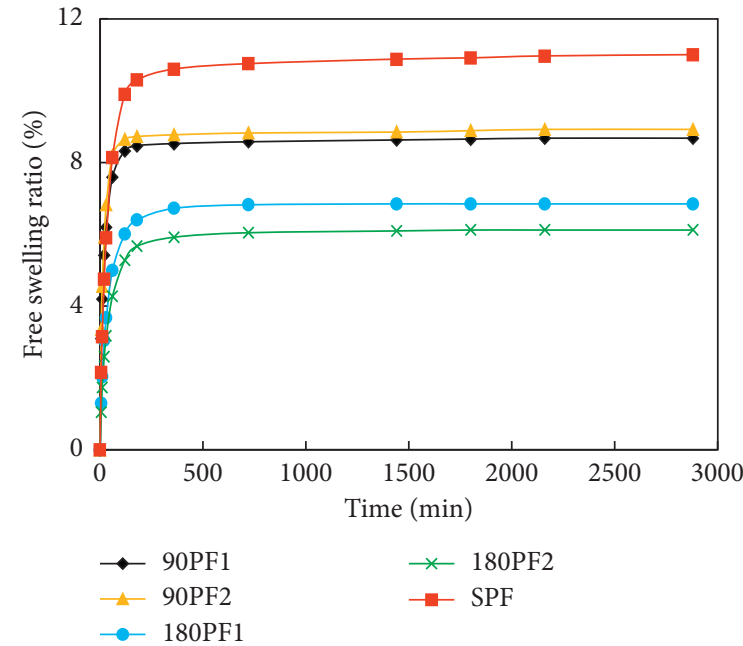

(f)

FiguRe 7: The expansion rate of soil in different soil layers varying with time: (a) $0 \sim 5 \mathrm{~cm}$; (b) $5 \sim 10 \mathrm{~cm}$; (c) $10 \sim 15 \mathrm{~cm}$; (d) $15 \sim 20 \mathrm{~cm}$; (e) 20 25; (f) 25 30 cm (90 and 180, the growth age; P, the root-soil composite sample; SP, the pure soil sample; a f, different sampling depths; 1 and 2, the parallel test group number).

Figures $7(\mathrm{a})$ and $7(\mathrm{~d})$ show that the expansion stability time of the $0 \sim 5 \mathrm{~cm}$ layer and the $15 \sim 20 \mathrm{~cm}$ layer root-soil composite is larger than that of pure soil, but the no-load expansion rate is smaller than that of pure soil. And, the noload expansion ratio decreases as the root content increases. This indicates that the reinforced effect of the vetiver root 


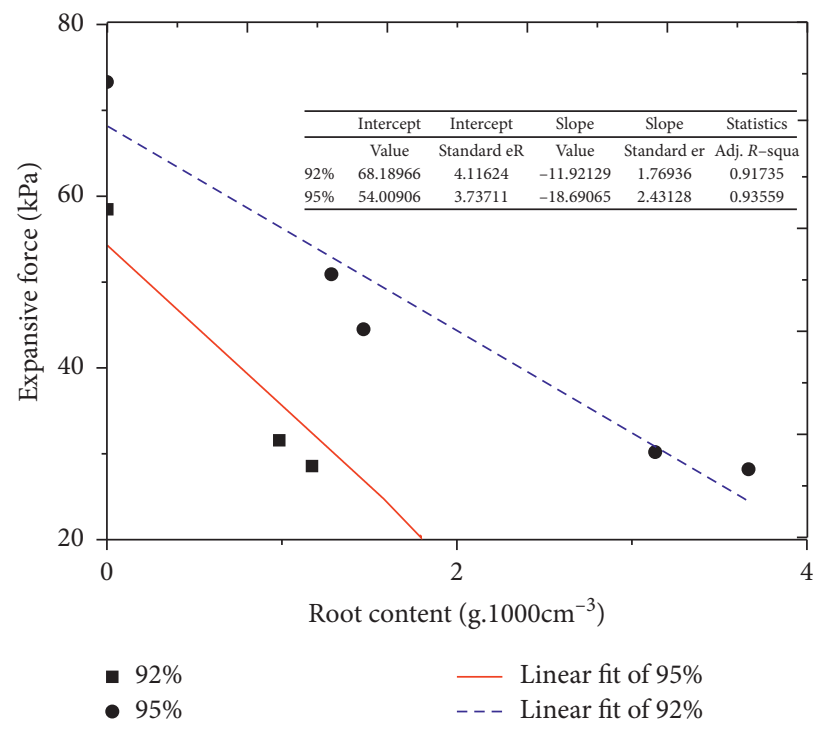

Figure 8: Relationship between expansive force and root content.

system can reduce the swelling property of the expansive soil. Due to the high degree of compactness of the two layers of soil samples, the blocking effect of the root system under high density [29] reduced the infiltration, thereby delaying the release of the expansion potential.

Figures $7(\mathrm{c})$ and $7(\mathrm{f})$ show that the height of $10 \sim 15 \mathrm{~cm}$ and $25 \sim 30 \mathrm{~cm}$ of the root-soil, the no-load expansion rate, and the expansion stability time were smaller than that of the pure soil, indicating that the vetiver root system accelerates the release of the expansion potential. However, this phenomenon is different from the result of the height of $0 \sim 5 \mathrm{~cm}$ and $15 \sim 20 \mathrm{~cm}$ of the root-soil. In addition, as the compactness decreased, permeability of the root-soil improved and the completion time shortened; in other words, the expansion stabilization time become shorter.

3.3. The Influence of Root System on the Expansive Force of Planted Root-Soil Complex. Table 2 shows the results of the expansive force test. In the same depth range, the density and the water content of the sample were the same. The results indicated that the number of added roots had a vital effect on the expansive forces of soils.

In Table 2, the swelling force of the rooted soil was determined for the depth range of $0-30 \mathrm{~cm}$ with $5 \mathrm{~cm}$ intervals, compared with that of the pure soil; in the situation of $90 \mathrm{~d}$, the swelling force rate reduction for the soot soil was $39.3 \%, 46.2 \%, 55.6 \%, 33.4 \%, 46.8 \%$, and $47.6 \%$, respectively, when compared with that of pure soil samples. In the situation of $180 \mathrm{~d}$, the swelling force rate reduction for the soot soil was $61.4 \%, 75.8 \%, 85.4 \%, 65.7 \%$, and $75.1 \%$, respectively. These results indicated that grass roots could reduce the expansive soil's expansive force. Lei et al. [30] carried out a test to investigate the influence of the hemp fiber on reinforced expansive soil and also verified this phenomenon. It indicates that the mechanism of vetiver root inhibition of expansion is similar to that of the fiber material. In all, the deformation of the soil is restricted by the wrapping action of the root network, and the friction between the root and the soil interface degrades and inhibits the partial expansive force.

In the same depth, as the root content increased, the expansive force of rooted soil decreased, which indicates that the number of added roots has an obvious impact on the expansive force.

In addition, although the root content of soil under the situation of $180 \mathrm{~d}$ was bigger than that of $90 \mathrm{~d}$, for different heights of soil, the expansive force reduction is not the same. Taking $0 \sim 5 \mathrm{~cm}$ and $25 \sim 30 \mathrm{~cm}$ layers as an example, in the situation of $90 \mathrm{~d}$, the maximum reduction of expansive force occurred in the height of $25 \sim 30 \mathrm{~cm}$, up to $47.6 \%$, and for $180 \mathrm{~d}$, this value was up to $75.1 \%$. The $25 \sim 30 \mathrm{~cm}$ layer has less root content and abundant fine roots, and its specific surface area is large. With an increase in the contact area in the rooted soil, there is an increase in the ability to reduce expansive force; in other words, as the surface area increased, the ability to inhibit the expansive force also increased.

However, compared to the situation of $180 \mathrm{~d}$, although the root content was bigger than that of $90 \mathrm{~d}$, in the height of $15 \sim 20 \mathrm{~cm}$, the reduction rate in expansive force in $90 \mathrm{~d}$ was bigger than that of $180 \mathrm{~d}$, and this is due to root-soil; fine roots with similar root mass have more roots and a larger specific surface area; therefore, the effect of fine root reinforcement is better than that of coarse roots with the same root mass.

Meanwhile, the average water content of the layers $0 \sim 5 \mathrm{~cm}$ and $5 \sim 10 \mathrm{~cm}$ was $17.02 \%$ and $17.58 \%$, respectively, and the water content was similar. The linear fitting of the layer's root content and expansive force, $R^{2}$, was 0.94 and 0.92 , respectively, and the linear slope was 18.69 and 11.92, respectively (Figure 8 ). It is clear that the root system has a significant effect on the inhibition of expansive force under the condition of low density. Under the condition of high compactness, soil particles are closely bound to each other, 
TABLE 2: Expansive force test results.

\begin{tabular}{|c|c|c|c|c|c|c|}
\hline Height & Category & Density $\left(\mathrm{g} \cdot \mathrm{cm}^{-3}\right)$ & Water content (\%) & Root content $\left(\mathrm{g} \cdot 1000 \mathrm{~cm}^{-3}\right)$ & Growth period (d) & Expansive force $(\mathrm{kPa})$ \\
\hline \multirow{5}{*}{$0 \sim 5 \mathrm{~cm}$} & \multirow[t]{2}{*}{ Pure soil } & 1.97 & 17.0 & - & - & 73.3 \\
\hline & & 1.96 & 17.3 & 1.467 & 90 & 44.5 \\
\hline & \multirow{3}{*}{ Root-soil } & 1.92 & 17.2 & 1.283 & 90 & 50.9 \\
\hline & & 1.95 & 16.9 & 3.133 & 180 & 30.2 \\
\hline & & 1.92 & 16.7 & 3.667 & 180 & 28.2 \\
\hline \multirow{5}{*}{$5 \sim 10 \mathrm{~cm}$} & \multirow[t]{2}{*}{ Pure soil } & 1.78 & 17.6 & - & - & 58.2 \\
\hline & & 1.76 & 17.8 & 0.983 & 90 & 31.3 \\
\hline & \multirow{3}{*}{ Root-soil } & 1.73 & 17.8 & 1.170 & 90 & 28.3 \\
\hline & & 1.78 & 17.1 & 2.267 & 180 & 14.1 \\
\hline & & 1.74 & 17.6 & 2.083 & 180 & 16.6 \\
\hline \multirow{5}{*}{$10 \sim 15 \mathrm{~cm}$} & \multirow[t]{2}{*}{ Pure soil } & 1.66 & 18.6 & - & - & 26.8 \\
\hline & & 1.65 & 18.5 & 0.583 & 90 & 12.0 \\
\hline & \multirow{3}{*}{ Root-soil } & 1.62 & 18.2 & 0.650 & 90 & 11.9 \\
\hline & & 1.63 & 18.2 & 1.706 & 180 & 3.9 \\
\hline & & 1.62 & 18.6 & 1.467 & 180 & 5.1 \\
\hline \multirow{5}{*}{$15 \sim 20 \mathrm{~cm}$} & \multirow[t]{2}{*}{ Pure soil } & 1.97 & 19.5 & - & - & 62.3 \\
\hline & & 1.98 & 19.1 & 0.444 & 90 & 45.2 \\
\hline & \multirow{3}{*}{ Root-soil } & 1.96 & 18.8 & 0.517 & 90 & 41.5 \\
\hline & & 1.97 & 19.4 & 0.983 & 180 & 21.4 \\
\hline & & 1.93 & 18.9 & 0.867 & 180 & 22.6 \\
\hline \multirow{5}{*}{$20 \sim 25 \mathrm{~cm}$} & \multirow[t]{2}{*}{ Pure soil } & 1.78 & 19.7 & - & - & 53.6 \\
\hline & & 1.74 & 19.5 & 0.383 & 90 & 28.5 \\
\hline & \multirow{3}{*}{ Root-soil } & 1.72 & 19.8 & 0.317 & 90 & 30.7 \\
\hline & & 1.77 & 19.8 & 0.653 & 180 & 19.0 \\
\hline & & 1.74 & 20.1 & 0.517 & 180 & 20.5 \\
\hline \multirow{5}{*}{$25 \sim 30 \mathrm{~cm}$} & \multirow[t]{2}{*}{ Pure soil } & 1.65 & 20.8 & - & - & 23.3 \\
\hline & & 1.65 & 20.3 & 0.217 & 90 & 12.2 \\
\hline & \multirow{3}{*}{ Root-soil } & 1.68 & 20.5 & 0.184 & 90 & 14.6 \\
\hline & & 1.67 & 20.7 & 0.451 & 180 & 7.2 \\
\hline & & 1.65 & 21.0 & 0.434 & 180 & 5.8 \\
\hline
\end{tabular}

which hinder the flow of water between particles and reduce the expansive force.

3.4. The Influence of Root System on the Dry Shrinkage Cracking for Grafted Soil. As shown in Figure 9, the maximum crack width on the surface of the sample changes with time. Figure 9 shows that, with the increase in the root content, the maximum crack width decreases and the number of cracks increases slowly, indicating that the root has the effect of inhibiting cracking. To quantitatively describe the inhibition effect of vetiver reinforcement on dry shrinkage cracks in expansive soil, the equation of crack width reduction rate $\left(P_{\mathrm{b}}\right)$ was introduced in this paper. $P_{\mathrm{b}}$ is defined as follows:

$$
P_{\mathrm{b}}=\frac{\left(P-P_{\mathrm{d}}\right) \times 100}{P}
$$

where $P$ is the maximum crack width of the soil sample without vetiver and $P_{\mathrm{d}}$ is the maximum crack width of vetiver reinforced soil.

After calculation, the maximum crack width reduction rate of the expanded soil samples with a root content of $0.78 \mathrm{~g} / 1000 \mathrm{~cm}^{3}, 1.56 \mathrm{~g} / 1000 \mathrm{~cm}^{3}, 2.34 \mathrm{~g} /$ $1000 \mathrm{~cm}^{3}$, and $3.12 / 1000 \mathrm{~cm}^{3}$ was $9.09 \%, \quad 77.27 \%$, $88.64 \%$, and $97.73 \%$, respectively. It indicated that the root system of vetiver could inhibit the shrinkage crack

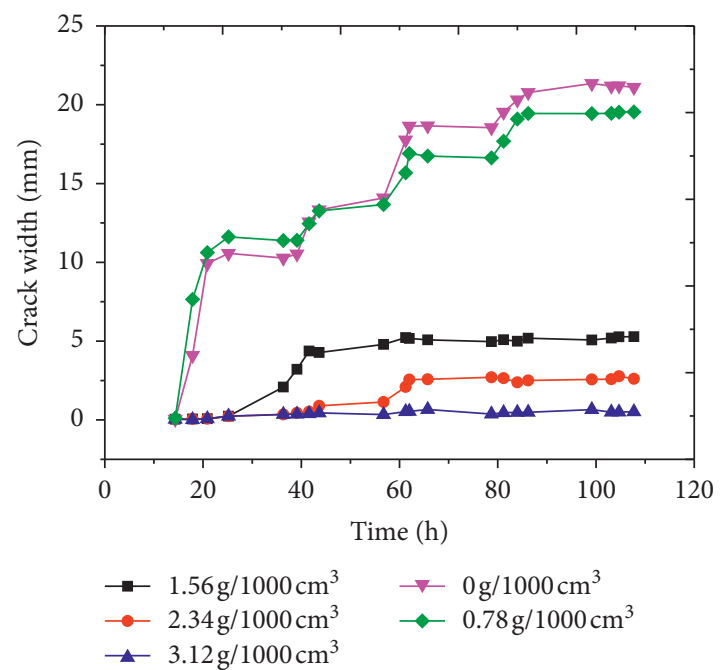

FIgURE 9: Variation of crack width on the surface of the sample.

of expansive soil, and the higher the root content, the more obvious the effect.

Figure 10 shows the shrinkage cracks of rooted soil with different root contents: for no rooted soil and a root content of $0.78 \mathrm{~g} / 1000 \mathrm{~cm}^{3}$. All soils were penetrated from the surface to the bottom, and the samples were divided 


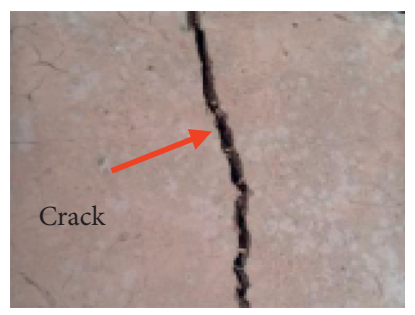

(a)

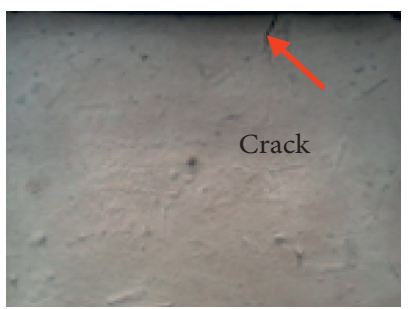

(d)

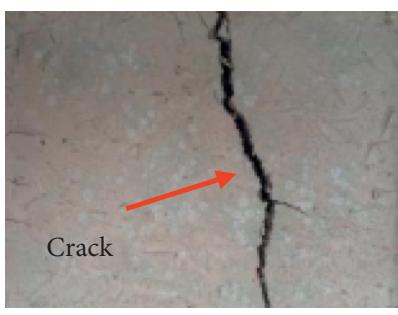

(b)

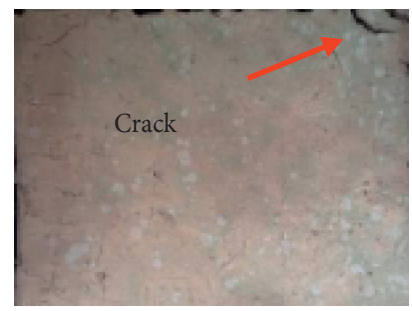

(c)

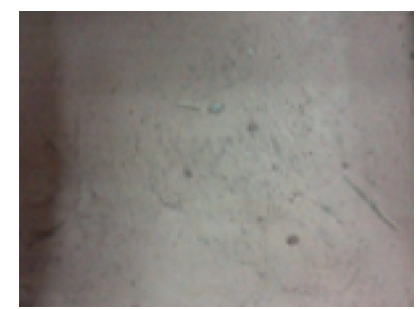

(e)

FIgURE 10: Dry shrinkage cracks on the surface of composite root-soil of vetiver roots with different root contents: (a) pure soil; (b) root content is $0.78 \mathrm{~g} / 1000 \mathrm{~cm}^{3}$; (c) root content is $1.56 \mathrm{~g} / 1000 \mathrm{~cm}^{3}$; (d) root content is $2.34 \mathrm{~g} / 1000 \mathrm{~cm}^{3}$; (e) root content is $3.12 \mathrm{~g} / 1000 \mathrm{~cm}^{3}$.

into two parts. As the root content increased, the development of the cracks became decreased and was only found in the shallow surface. Because the inhibition was enhanced by the roots, the development of the cracks is only found in the shallow surface. When the root content was up to $3.12 \mathrm{~g} / 1000 \mathrm{~cm}^{3}$, no obvious cracks appeared on the surface of the sample, and only a small amount of fine cracks was found.

The grafted root system has the effect of inhibiting the cracking of the expansive soil, and within a certain root content range, the greater the root content, the more obvious the effect of inhibiting the cracking, and the actual planted root system should have a stronger inhibitory effect than the grafted root. So, what is the relationship between expansive force or expansion rate and cracking?

\subsection{Mechanism of Vegetation Root Inhibiting the Cracking of Expansive Soil}

3.5.1. Enhancing Soil Bonding. Due to root interspersed and intertwined from the pores of the soil, which provides a good overall encapsulation effect for the soil particles. As shown in Figure 11, the expansion soil will have a strong interparticle combination, especially the large number of capillary roots derived from the main root system. This function can intersperse and wrap the surrounding soil layer. Thereby, the root greatly increases the shear strength of the soil and improves the tensile strength of the soil and then inhibits cracking. The cohesive force in the shear strength parameters is mainly produced by cementation, which is formed by the longterm geological action of the geotechnical. Once the failure surface is formed during the stress process, the cohesive force would be considered to lose. And, these characteristics are unrecoverable in a short term. Tang et al. [31] pointed out that when the soil is subjected to

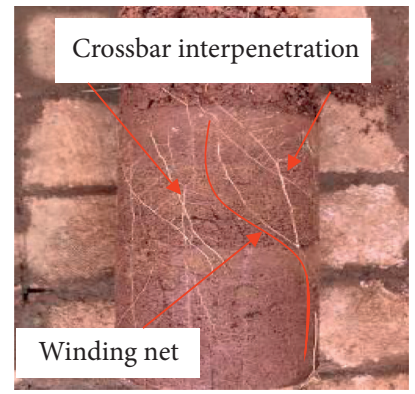

FIgURE 11: Soil wrapped by roots.

tensile force, it would overcome the attraction between the particles and the chemical bonding force, as well as the surface tension and the attractiveness of the water in the soil. Zhang and Chen [32] found that there is a certain correlation between tensile strength and the shear force state of the soil, that is, the tensile strength increases with the increase in cohesion. Zhu et al. [33] found that there is a certain degree of linear correlation between tensile strength and shear strength of unsaturated cohesive soils. Zhu [34], Li [35], and Tang et al. [36] also found similar laws, which showed that the entanglement of the root system improves the soil binding force and also increases the tensile strength of the soil. Thus, tensile strength is one of the key factors which affect soil cracking [1]. When the lateral shrinkage stress is greater than the sum of the tensile strength and the lateral compressive stress caused by the soil self-weight stress, the crack is generated. Because the root system could increase the tensile strength of the expansive soil, the cracking of the expansive soil can be suppressed to some extent.

3.5.2. Reducing the Soil's Expansive Force and Expansion Rate. On the one hand, the action of root wrapping reduces 
the expansion of the expansive soil, and on the other hand, it inhibits the expansive force. The root system reduces the expansibility and inhibits the cracking. Liu et al. [37] found that the gray entropy of the crack image on the surface of expansive soil increases with the increase in the expansion rate, and the larger the gray entropy, the greater the degree of crack development. At the same time, this research also found that the greater the expansion, the lower the strength of the expansive soil and the lower the strength. The expansive soil was more susceptible to cracking when the soil strength was low. Liu et al. [38] found that the ultimate fracture development of expansive soil is limited by load and is related to its own expansive force. The larger the expansive force, the larger the average length of the unit crack. The root system can reduce expansive force and unit crack length. Thereby, the soil cracking would be inhibited to a certain extent.

3.5.3. Extrusion of the Root System. The growth of the root system is from fine to thick, and this process will make the surrounding soil extruded. When the roots grow, the axial force generated by the root tip to the surrounding soil expands in a cylinder behind the root tip and is a kind of pressure [39]. Under the constraint of the confinement, fitting makes the expansive soil more compact. Liu et al. [40] showed that the greater the initial compaction degree, the smaller the fracture rate and total crack length of the expansive soil.

3.5.4. Atmosphere-Vegetation-Soil Interaction. Wu [41] showed that plant transpiration could increase soil suction, which would reduce the soil permeability coefficient and increase shear strength. After 20 days of the transpiration test, it was found that the maximum suction force in the grass vegetation soil could reach 1.3 times than that of the bare soil, which also increased the shear strength of the soil by about $30 \%$. At the same time, the suction effect of grass vegetation soil can reach more than three times in the depth of grass roots. The relationship between shear strength and cracking has been explained in Section 3.5.1. It is clear that the transpiration inhibits the cracking of expansive soil. This result also showed that the actual root system has a more obvious effect on the inhibition of expansion cracking.

\section{Conclusions}

(1) The wrapping action of vegetation roots can significantly reduce the expansion rate and expansive force of expansive soil. Under the conditions of this experiment, the expansive force of planting root expansive soil growing for $180 \mathrm{~d}$ and $90 \mathrm{~d}$ decreased by $85.4 \%$ and $55.6 \%$, respectively, compared with that of plain expansive soil, and the no-load expansion rate decreased by $70.9 \%$ and $59.1 \%$, respectively.

(2) The higher the root content of vetiver root and the lower the compactness of expansive soil, the more obvious the effect of the root to restrain the expansion rate and reduce the expansive force. Under the same root content, the effect of fine roots on the inhibition of expansion can reach $75.1 \%$, and it was better than that of coarse roots which can reach $33.4 \%$. In the soil with high compactness, the root system could delay the release of the expansion potential. However, in the soil with low compactness, the root system could accelerate the release of the expansion potential.

(3) The maximum crack width reduction rate of the expansive soil samples with a root content of $0.78 \mathrm{~g} /$ $1000 \mathrm{~cm}^{3}, \quad 1.56 \mathrm{~g} / 1000 \mathrm{~cm}^{3}, \quad 2.34 \mathrm{~g} / 1000 \mathrm{~cm}^{3}$, and $3.12 / 1000 \mathrm{~cm}^{3}$ was $9.09 \%, 77.27 \%, 88.64 \%$, and $97.73 \%$, respectively. The effect of the vetiver root on inhibiting dry shrinkage cracking of expansive soil is more obvious with the increase in the root content.

(4) In this study, when the root content is increased to $3.12 \mathrm{~g} / 1000 \mathrm{~cm}^{3}$, the expansive soil will no longer crack. Considering the transpiration of vegetation, the inhibition of planting roots on the cracking of expansive soil will be more obvious.

(5) From the surface down, the inhibition effect of the vetiver root on the expansive soil appeared from low to high and then decreased; the effect was optimal in the layer of $10 \sim 15 \mathrm{~cm}$.

The reinforcement effect of the actual root system is not only related to root diameter and root content, but also related to root distribution direction, root quality, root length, and so on. These factors not considered in this paper need further research in the future.

\section{Data Availability}

All data included in this study are available upon request by contacting the corresponding author.

\section{Conflicts of Interest}

The authors declare that they have no conflicts of interest to this work.

\section{Acknowledgments}

The research reported in this manuscript was funded by the Natural Science Foundation of China (Grant no. 51578082) and the Hunan Graduate Innovation Foundation (Grant no. CX2018B535).

\section{References}

[1] Z. Z. Yin, J. P. Yuan, J. Wei, X. S. Cao, H. Q. Liu, and B. Xu, "Influence of fractures on stability of expansive soil slope," Chinese Journal of Geotechnical Engineering, vol. 34, pp. 2155-2161, 2012.

[2] L. Y. Zhang, T. L. Chen, and D. L. Zhang, "Study on progressive failure of expansive soil slope induced by rainfall," Journal of Geotechnical Engineering, vol. 41, pp. 76-83, 2019.

[3] Q. H. Wu, J. F. Zhang, J. B. Wu, and X. Y. Liu, "Physical model test of unsaturated drainage structure controlling rainfall 
infiltration," Journal of Geotechnical Engineering, vol. 39, pp. 160-166, 2017.

[4] S. Liu, F. Bai, Y. Wang, S. Wang, and Z. Li, "Treatment for expansive soil channel slope with soilbags," Journal of Aerospace Engineering, vol. 26, no. 4, pp. 657-666, 2013.

[5] C. Q. Shun and K. V. Sai, "Hydro-mechanical coupling effect on surficial layer stability of unsaturated expansive soil slopes," Computers and Geotechnics, vol. 70, pp. 68-82, 2015.

[6] Y. Y. Qi, "Numerical simulation of the stability of added lime expansive soils embankment," Advanced Materials Research, vol. 838-841, pp. 821-824, 2014.

[7] G. Q. Ding and J. P. Yuan, “Analysis of protective mechanism of expansive soil slope and comparison of protective methods," Journal of Geotechnical Engineering, vol. 32, pp. 33-37, 2018.

[8] X. W. Li, A. J. Wang, and Y. Wang, "Indoor simulation test of moisture and heat and fracture characteristics of expansive soil under rainfall evaporation," Rock and Soil Mechanics, vol. 35, pp. 46-51, 2014.

[9] C. Xie, P. Ni, M. Xu, G. Mei, and Y. Zhao, "Combined measure of geometry optimization and vegetation for expansive soil slopes," Computers and Geotechnics, vol. 123, Article ID 103588, 2020.

[10] H. Rahardjo, N. Amalia, L. E. Choon, F. R. Harnas, L. T. Tieng, and F. Y. King, "Flux boundary measurements for the study of tree stability," Landscape and Ecological Engineering, vol. 13, no. 1, pp. 81-92, 2017.

[11] H. Rahardjo, A. Satyanaga, C. L. Wang, J. L. H. Wong, and V. H. Lim, "Effects of unsaturated properties of soil with Caesalpinia crista roots on slope stability," Environmental Geotechics, pp. 1-11, 2018.

[12] T. Liang, A. G. Bengough, J. A. Knappett et al., "Scaling of the reinforcement of soil slopes by living plants in a geotechnical centrifuge," Ecological Engineering, vol. 109, pp. 207-227, 2017.

[13] T. Liang and J. A. Knappett, "Centrifuge modelling of the influence of slope height on the seismic performance of rooted slopes," Géotechnique, vol. 67, no. 10, pp. 1-15, 2017.

[14] T. Liang, J. A. Knappett, A. G. Bengough, and Y. X. Ke, "Small-scale modelling of plant root systems using 3D printing, with applications to investigate the role of vegetation on earthquake-induced landslides," Landslides, vol. 14, no. 5, pp. 1747-1765, 2017.

[15] G. Y. Wang, H. Zhou, Y. Q. Xia, L. C. Sha, and H. G. Zhou, "Effects of grass roots on slope soil strength and disintegration characteristics," Chinese Journal of HighWays, vol. 31, pp. 238-245, 2018.

[16] H. D. Gray, "Reinforcement and Stabilization of soil by vegetation," International Journal of Rock Mechanics and Mining Sciences \& Geomechanics Abstracts, vol. 11, no. 10, p. 214, 1974.

[17] D. N. Swanston, G. W. Lienkaemper, R. C. Mersereru, and A. B. Levno, "Timber harvest and progresive deformation of slope in southwest Oregon," Environmental \& Engineering Geoscience, vol. 25, no. 3, pp. 371-381, 1988.

[18] E. A. Skaugset, "Modeling root reinforcement in shalolow forrest soil," M.S. thesis, Oregon State University, Corvallis, Oregon, 1997.

[19] J. Roeriing, M. K. Schmidt, and D. J. Stock, "Root Reinforcement, and the spatial distribution of tree in the Oregon coast range," Canadian Geotechnical Journal, vol. 40, pp. 237-253, 2003.

[20] S. J. Martel, "Machanics of landslide initiation as a shear fracture phenomenon," Marine Geology, vol. 203, no. 3-4, pp. 319-339, 2004.
[21] G. Y. Wang, L. C. Sha, W. G. Cao, Y. J. Zhang, and Q. S. Tang, "Experimental study on cracking characteristics of rice straw reinforced soil with reinforcement rate," Journal of Hydrogeology Engineering Geology, vol. 44, pp. 52-58, 2017.

[22] L. Li, "Effects of plant roots on clay mulch," M.S. thesis, Harbin Institute of Technology, Harbin, China, 2015.

[23] Z. Y. Zhang, W. Y. Zhu, L. Zhu, C. Wang, L. T. Sheng, and Y. Chen, "Effects of root and salt content on the development of dry shrinkage cracks in farmland soil," Chinese Journal of Agricultural Engineering, vol. 30, pp. 83-89, 2014.

[24] Y. Zhou, J. Chen, and X. Wang, "Research on resistance cracking and enhancement mechanism of plant root in slope protection by vegetation," Journal of Wuhan University, vol. 55, pp. 613-618, 2009.

[25] M. N. Noorasyikin and M. Zainab, "A tensile strength of Bermuda grass and vetiver grass in terms of root reinforcement ability toward soil slope stabilization," IOP Conference Series: Materials Science and Engineering, vol. 136, Article ID 012029, 2016.

[26] Q. Guo, J. T. Li, and Y. M. Mei, "Study on the treatment and protection of highway slope in expansive land segment by biotechnology," Highway Traffic Science and Technology (Applied Technology Edition), vol. 12, pp. 144-145, 2006.

[27] Y. H. Bao, C. R. Bai, and W. Chen, "Protection of landslide slope by vetiveria vetiana and locust green hedge," Highway, vol. 4, pp. 73-75, 2001.

[28] C. Zhou, Y. Z. Lu, and Y. H. Huang, "Lateral limit expansion and direct shear test of vetiver grass reinforced expansive soil with different moisture content," Chinese Journal of Geotechnical Engineering, vol. 38, pp. 30-35, 2016.

[29] Y. Xie, Z. H. Chen, S. G. Sun, G. Li, and X. W. Fang, "Experimental study on three-dimensional expansion force of remolded expansive soil," Geotechnical Mechanics, vol. 8, pp. 115-121, 2007.

[30] S. Y. Lei and W. T. Ding, "Test of reinforced fiber to restrain the expansibility of expansive soil," Chinese Journal of Geotechnical Engineering, vol. 27, pp. 482-485, 2005.

[31] W. Tang, H. Xia, and J. Luo, "Theoretical analysis on the source of tensile strength of unsaturated soil," Anhui Agricultural Science, vol. 43, pp. 372-374, 2015.

[32] Y. Zhang and M. Y. Chen, "Study on tensile strength of compacted clay," Hydrogeology Engineering Geology, vol. 42, pp. 56-60, 2015.

[33] C. H. Zhu, J. M. Liu, B. W. Yan, and J. J. Li, "Experimental study on the relationship between tensile strength and shear strength of unsaturated clay," Journal of Rock Mechanics and Engineering, vol. 27, pp. 3453-3458, 2008.

[34] A. L. Zhu, "Experimental study and numerical simulation of tensile strength of cohesive Soil," M.S. thesis, Sichuan University, Sichuan, China, 2005.

[35] S. C. Li, "Study on latt resistance of loess," M.S. thesis, Northwest University of Agriculture and Forestry, Shanxi, China, 2005.

[36] L. S. Tang, "Recognizing the theory of shear strength of unsaturated soils from the characteristics of intergranular suction," Journal of Geotechnical Engineering, vol. 23, pp. 412-417, 2001.

[37] S. L. Liu, B. Xu, and Z. Z. Yin, "Experimental study on the effect of expansibility on the strength of expansive soil," Journal of Henan University of Science and Technology (Natural Science Edition), vol. 46, pp. 72-78, 2018.

[38] W. Liu, Q. Yin, N. Fang, Y. Cheng, and C. Liu, "The relationship between the development of fissures in expansive soils and the state of soils," Journal of Kunming Metallurgical College, vol. 34, pp. 5-10, 2018. 
[39] L. Hu, F. Wang, X. M. Li, X. M. Mu, and Z. Y. Song, "Design of a test device for measuring the mechanical pressure of roots on soil," Soil and Water Conservation Research, vol. 17, pp. 138-141, 2010.

[40] G. S. Liu, Y. G. Chen, and G. B. Zhang, "Experimental study on the effect of compaction conditions on the development of fissures in expansive soils," Journal of Yangtze Academy of Sciences.

[41] H. W. Wu, "Atmosphere-vegetation-soil interaction: theory and mechanism," Chinese Journal of Geotechnical Engineering, vol. 39, pp. 1-47, 2017. 